\title{
The Ti-MWW catalyst - its characteristic and catalytic properties in the epoxidation of allyl alcohol by hydrogen peroxide
}

\author{
Agnieszka Wróblewska ${ }^{1}$, Anna Fajdek ${ }^{1}$, Eugeniusz Milchert ${ }^{1}$, Barbara Grzmil ${ }^{2}$ \\ West Pomeranian University of Technology, Szczecin, ul. Pulaskiego 10, 70-322 Szczecin, Poland, \\ e-mail: Agnieszka.Wroblewska@zut.edu.pl \\ ${ }^{1}$ Institute of Organic Chemical Technology, \\ ${ }^{2}$ Institute of Inorganic Chemical Technology and Environmental Engineering
}

\begin{abstract}
Ti-MWW, one of the latest titanium-silicalite catalysts, has been prepared by direct hydrothermal synthesis using hexamethyleneimine as a structure-directing agent. The characteristic of the catalyst was performed by means of the following methods: XRD, SEM, IR, UV-vis and X'Ray microanalysis. The catalytic properties of Ti-MWW have been compared with those of the conventional titanium-silicalites TS- 1 and TS-2 in the epoxidation of allyl alcohol with hydrogen peroxide. The process has been described by the following main functions: the selectivity of the transformation to glycidol in relation to allyl alcohol consumed, the conversions of the substrates (allyl alcohol and hydrogen peroxide) and the selectivity of the transformation to organic compounds in relation to hydrogen peroxide consumed.
\end{abstract}

Keywords: Ti-MWW, titanium-silicalites, glycidol, liquid phase epoxidation, hydrogen peroxide

\section{INTRODUCTION}

An important structural parameter of the zeolites is the size of the pore opening through which organic molecules diffuse into channels and cages of zeolite to active centers. It limits the possibility of using the catalysts in organic reactions, especially in epoxidation processes ${ }^{1}$.

Since titanium-containing zeolite with MFI structure (TS-1) was synthesized using hydrothermal synthesis method by Taramasso et al. ${ }^{2}$ in 1983, much attention has been focused on the TS- $1 / \mathrm{H}_{2} \mathrm{O}_{2}$ reaction system owing to its environmentally benign and outstanding oxidation selectivity. The next synthesized titanium-silicalite catalysts were: TS-2 (the pore size $0.5 \mathrm{~nm}$ - the same as TS- 1 ), TiBeta (the pore size $0.7 \mathrm{~nm}$ ). Silicates Ti-MCM- 41 and TiMCM-48 (the pore size depends on template, the catalysts synthesized by us had the pore size $1.3 \mathrm{~nm}$ ) have similar properties. These catalysts were discovered because the researchers were looking for the catalyst having larger pore size than TS-1 and they will be used for the epoxidation of bulky and branched organic molecules. Ti-MWW ${ }^{3}$ belongs to the latest titanium-silicalite catalysts.

The new titanium-silicalite Ti-MWW catalyst structure is built from a lamellar precursor undergoing dehydroxylation upon calcinations between the layered sheets (Figure 1). Besides two-dimensional sinusoidal channels of 10-membered rings (MR) running throughout the structure parallel to the $a b$-plane, the MWW structure contains an independent channel system which is comprised of large supercages $0.7 \times 0.7 \times 1.8 \mathrm{~nm}$. The supercages turn out to be pocket or cup moieties $0.7 \times$ $0.7 \mathrm{~nm}$ at the crystal exterior. This may provide potential opportunities for a wide variety of applications in petrochemical and fine chemical industries ${ }^{4-5}$.

Ti-MWW is the active catalyst in: epoxidation of linear alkenes $^{6}$ and allyl alcohol ${ }^{7}$ with hydrogen peroxide, oxidation of cis- and trans-2-hexenes $^{8,9}$, epoxidation of bis(allyl) ether (DAE) to allyl glycidyl ether (AGE) and diglycidyl ether (DGE) with aqueous hydrogen peroxide ${ }^{\mathbf{1 0}}$ and liquid-phase ammoxidation of cyclohexanone to oxime ${ }^{11}$.

The aim of this work was the synthesis of Ti-MWW. The next step was the application of Ti-MWW catalyst in the epoxidation of allyl alcohol over Ti-MWW catalyst and comparison of these results with those obtained over TS- 1 and TS- 2 catalysts.
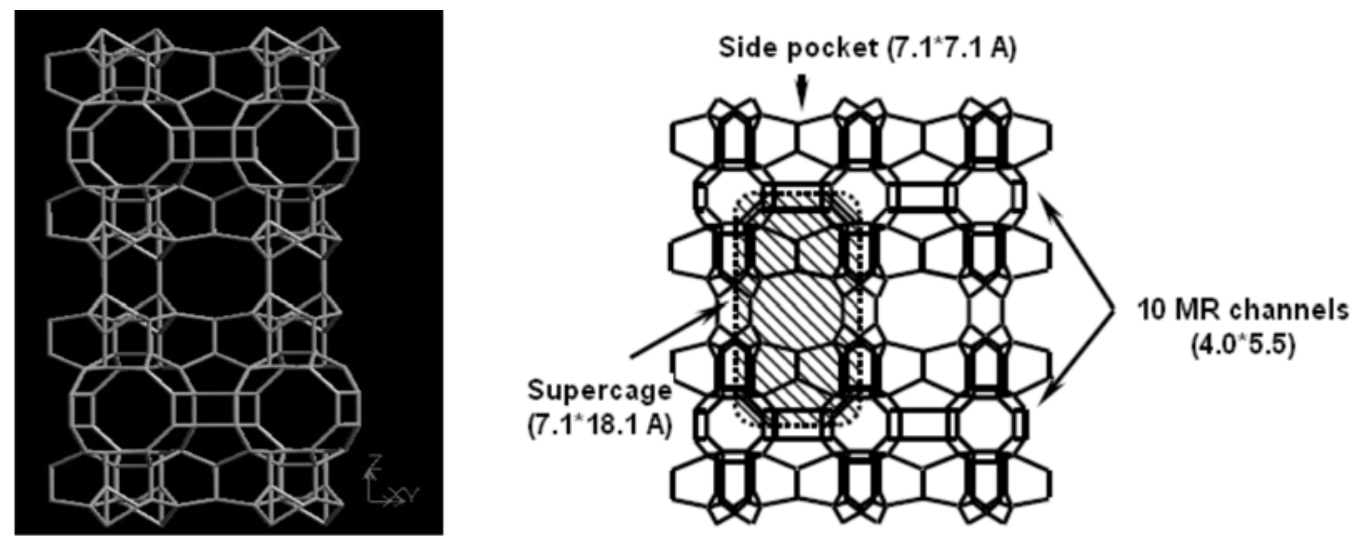

Figure 1. Topology of Ti-MWW zeolite ${ }^{5}$ 


\section{EXPERIMENTAL}

\section{Preparation of Ti-MWW catalyst and its characteristics}

For the synthesis of titanium-silicalite Ti-MWW catalyst the following raw materials: tetrabutyl o-titanate (TBOT, $\mathrm{Ti}(\mathrm{OBu})_{4}, 95 \%$, Fluka), hexamethyleneimine ( $\mathrm{HMI}, \mathrm{C}_{6} \mathrm{H}_{13} \mathrm{~N},>98 \%$, Merck), boric acid $\left(\mathrm{H}_{3} \mathrm{BO}_{3}\right.$, 99.5\%, Chempur), and fumed silica (Cab-o-sil M5, Biesterfeld)) were applied.

The Ti-MWW catalyst was synthesized by the method of Wu et al. ${ }^{12}$ : hexametyleneimine (HMI) was dissolved in deionized water at room temperature. This solution was divided into two equal parts, to one tetrabutyl otitanate $\mathrm{Ti}(\mathrm{OBu})_{4}$ was added, and to the other boric acid was added under vigorous stirring. The stirring was maintained for $30 \mathrm{~min}$ to hydrolyze tetrabutyl o-titanate. Fumed silica (Cab-o-sil M5) was divided into two equal parts which were added gradually to the solutions containing $\mathrm{Ti}$ (titanium) and B (boron), respectively. A further stirring for 1 hour was allowed to form two homogeneous gels. The gels were then mixed together and stirred for 1.5 hours to obtain a gel. The resulting gel was transformed into a PTFE-lined autoclave (Berghof) and heated with a stirring rate of $150 \mathrm{rpm}$ at $170^{\circ} \mathrm{C}(443 \mathrm{~K})$ for 14 days. After cooling, the solid product was filtered off and washed with deionized water to $\mathrm{pH}<9$. The product was then dried at $50^{\circ} \mathrm{C}(323 \mathrm{~K})$ for $2-3$ days. To remove boron and extraframework Ti species, an acid treatment with $2 \mathrm{M}$ $\mathrm{HNO}_{3}$ solution was carried out at $100^{\circ} \mathrm{C}(373 \mathrm{~K})$ for 20 hours at a solid-liquid ratio of $1 \mathrm{~g}$ to $20 \mathrm{ml}$. Then the product was dried at $50^{\circ} \mathrm{C}(323 \mathrm{~K})$ for $2-3$ days and calcined at $530-550^{\circ} \mathrm{C}$ to burn off any residual organic species.

The stages of the synthesis of Ti-MWW catalyst can be generally presented as follows:

the synthesis of Ti-MWW gel $\rightarrow$ crystallization of the gel $\rightarrow$ washing with deionized water to $\mathrm{pH}<9$ and drying $\rightarrow$ acid treatment to remove boron $\rightarrow$ calcination.

The Ti-MWW catalyst was investigated by means of the XRD method (the X-ray diffraction spectroscopy) on $X$ 'Pert PRO Philips diffractometer using $\mathrm{CuK} \alpha$ radiation. This method allows to establish the type of crystalline structure of the catalyst. The XRD patterns of the TiMWW catalyst (Figure 2) were totally consistent with the XRD patterns of Ti-MWW presented in literature ${ }^{4}$. The peaks at $2 \theta=5-7^{\circ}$ are characteristic of a lamellar structure along $c$-direction - Figure 2a. Other peaks are related with the crystalline sheets parallel to the $a b$-planes. Peak $6.57^{\circ}$ disappeared after acid treatment and calcination, while the peaks of $7.27^{\circ}$ and $8.02^{\circ}$ remained unchanged. This indicates that calcination only affected the c-axis structure, that is, calcination caused the loss of the laminar structure and the formation of the ordered linkage between the sheets through oxygen bridges (-O- $)^{4}$. The peaks $2 \theta=7-10^{\circ}$ and $2 \theta=25-27^{\circ}$ for the Ti-MWW after acid treatment and calcination are weaker than those of Ti-MWW after crystallization (Figure 2b). The lower crystallinity may arise from a small amount of framework defect sites generated by removing the organic species of $\mathrm{B}$ and Ti by the acid treatment ${ }^{4}$.

Scanning electron micrographs (SEM method) of the Ti-MWW catalyst are shown in Figure 3. The micro- a)

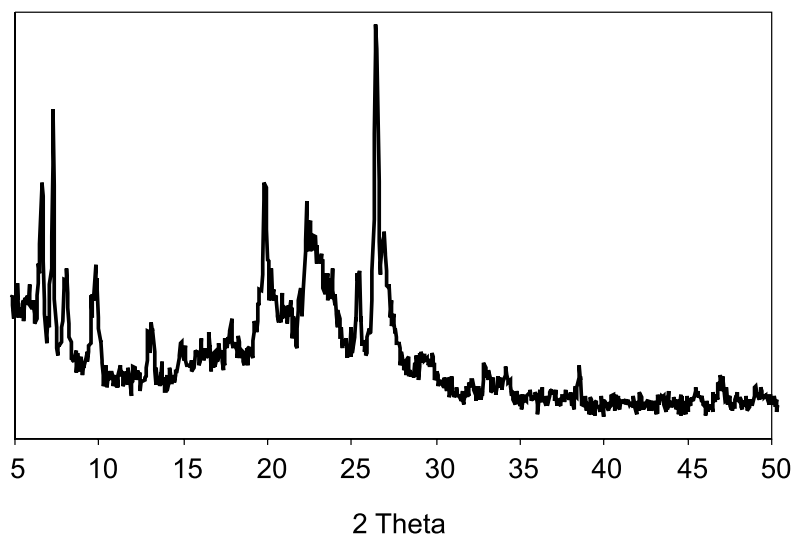

b)

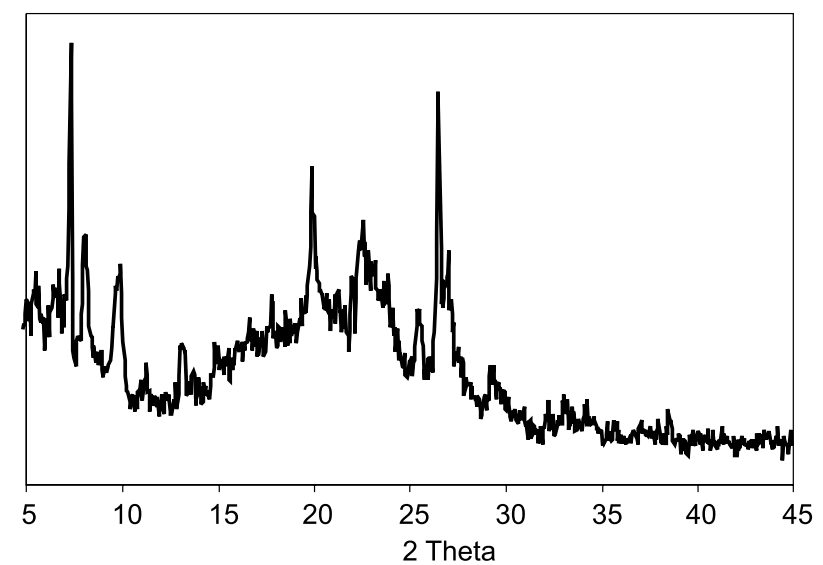

Figure 2. XRD patterns of the Ti-MWW obtained using hexamethyleneimine as a template: a) after crystallization and b) after acid treatment and calcination

graphs were made on JOEL JSM-6100 instrument. All the crystals appeared to be thin plates that mainly exhibited the hexagonal morphology. The thin plates of the TiMWW samples are approximately $2.5 \mu \mathrm{m}$ in length and $0.3 \mu \mathrm{m}$ in thickness and form aggregates. The calcination does not change the shape and size of the crystals.

The IR investigations were made on Shimadzu FTIR8100 spectrometer using the $\mathrm{KBr}$ pellet technique and are the same as in the literature ${ }^{4}$. The IR method is frequently employed to characterize the framework tetrahedral $\mathrm{Ti}$ in Ti-containing molecular sieves due to a characteristic band at $960 \mathrm{~cm}^{-1}$, which is assigned to the vibration of Si-O-Ti. The Ti-MWW sample, especially after acid treatment, contained a high concentration of defect sites such as hydroxyl nests generated on the vacancy of the framework $\mathrm{B}$ and Ti (band around $3450 \mathrm{~cm}^{-1}$ ) - Figure 4. The tetrahedral framework B develops two strong Si-O-B stretching bands: $1400 \mathrm{~cm}^{-1}$ and $940 \mathrm{~cm}^{-1}$, the latter of which overlaps the $960 \mathrm{~cm}^{-1}$ band to hinder the IR characterization of framework Ti species but after acid treatment it disappears. In the region of the zeolite framework vibration, the bands showing a cut off at $1000-1300 \mathrm{~cm}^{-1}$ is due to the Si-O-Si stretching vibration4.

The investigations by UV-VIS method was made on SPECORD M40 type V-530. As shown in Fig. 5, the UVvis spectrum of Ti-MWW after acid treatment and calcination shows the main band at $260 \mathrm{~nm}$. The band confirms the presence of $\mathrm{Ti}$ in tetrahedral coordination in the material. The other additional bands were not observed, especially the band around $330 \mathrm{~nm}$, which confirms the presence of anatase in the sample. 
a)
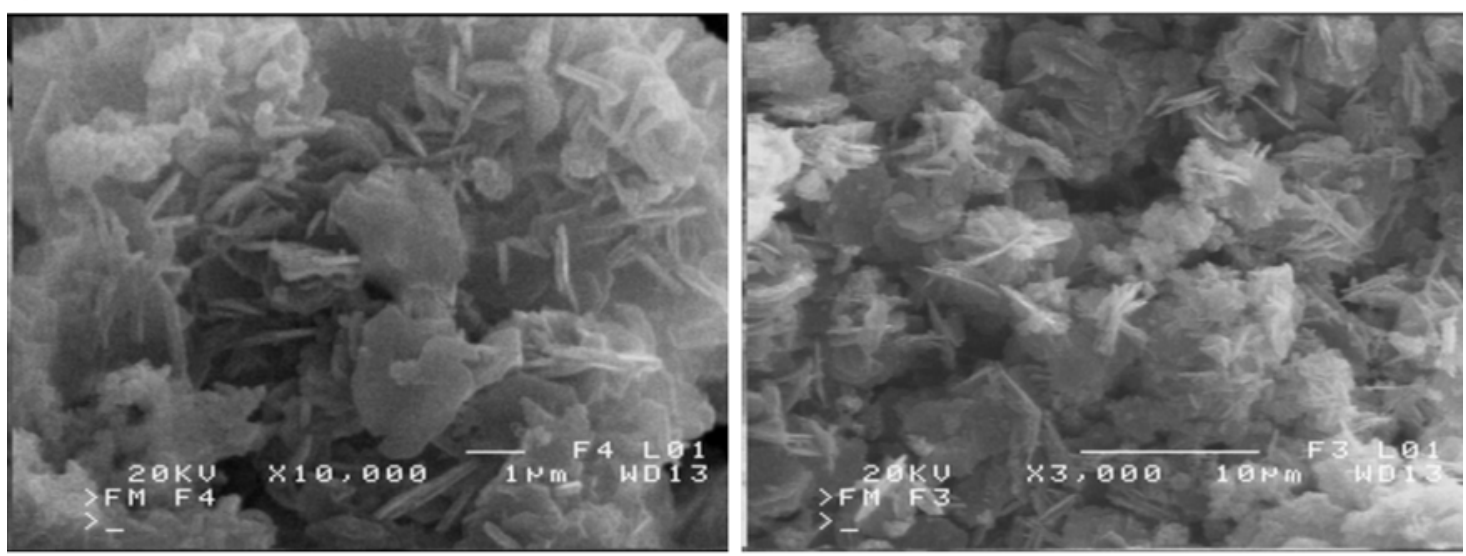

b)
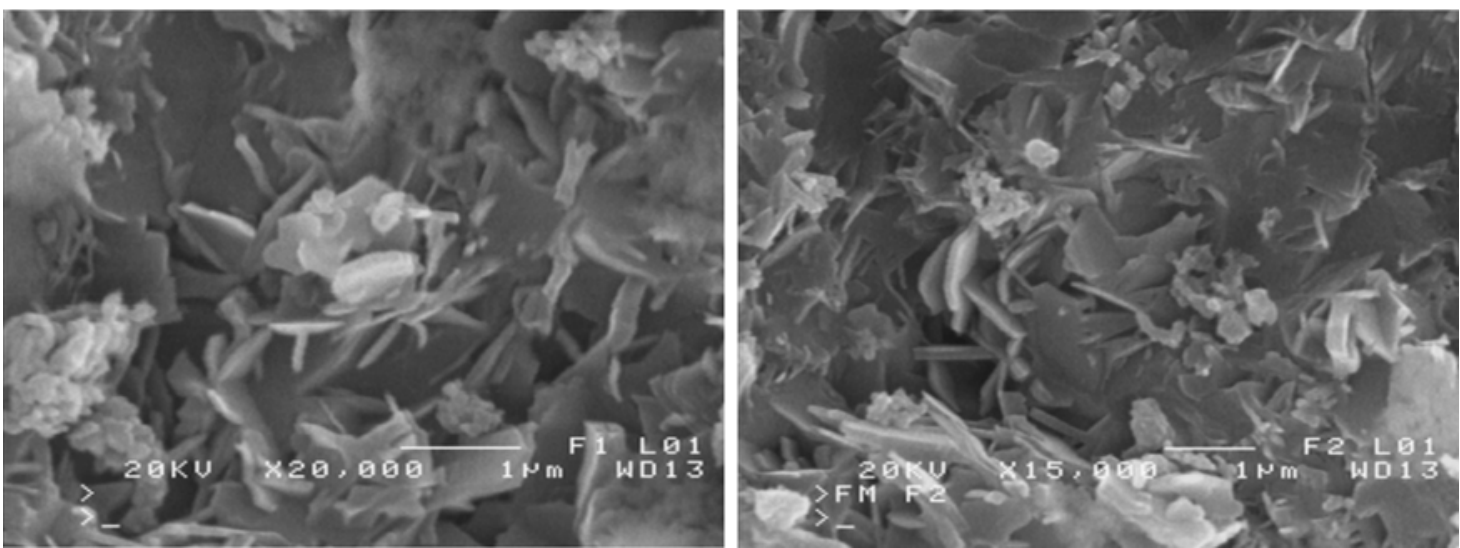

Figure 3. Scanning electron micrographs of the Ti-MWW catalyst obtained using hexamethyleneimine as a template: a) - after crystallization and b) - after acid treatment and calcination

a)

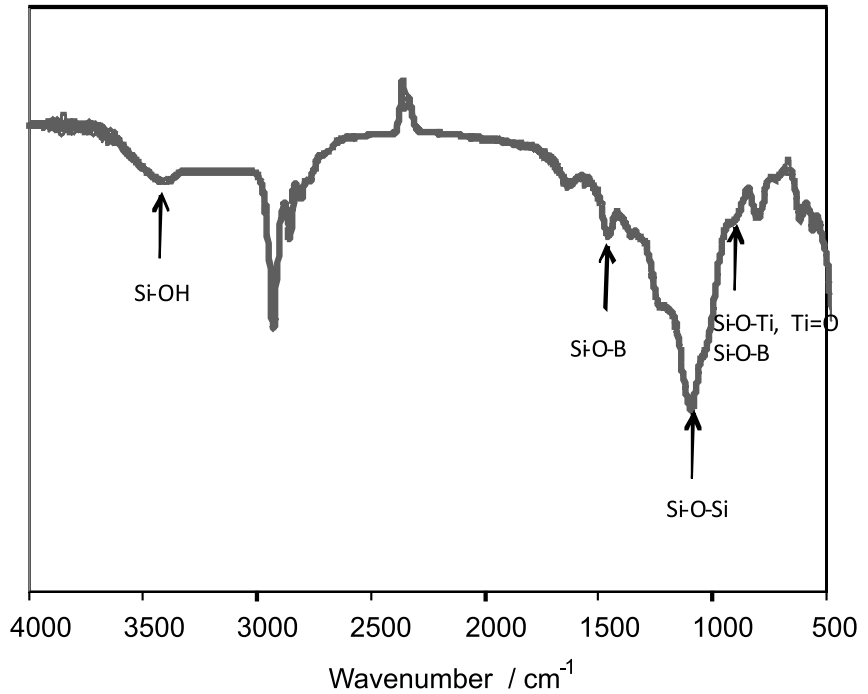

b)

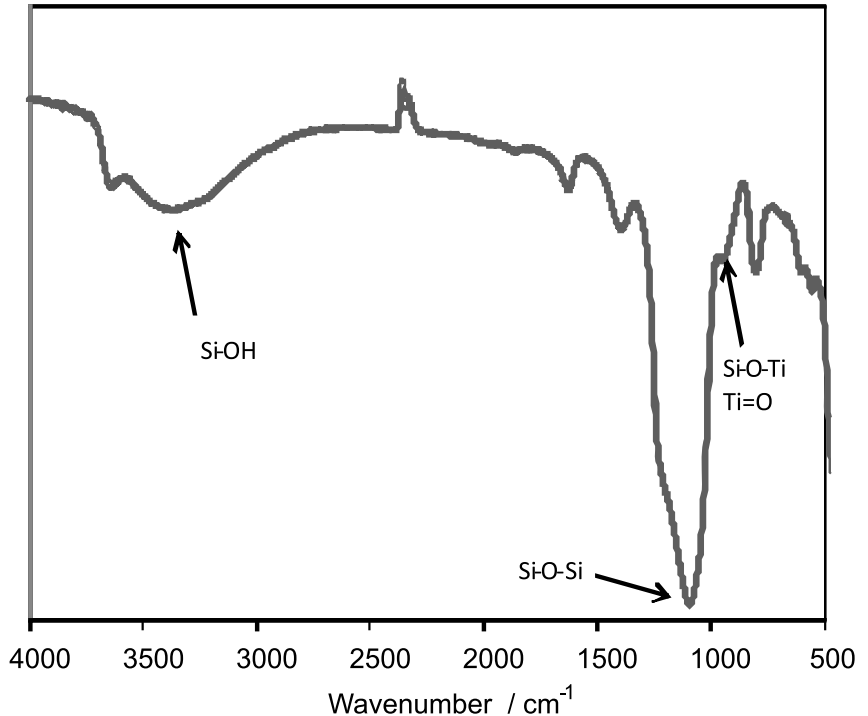

Figure 4. IR spectra of Ti-MWW catalyst obtained using hexamethyleneimine as a template: a) - after crystallization and b) - after acid treatment and calcination

The investigations by X-ray microanalysis was made on the Oxford X-ray analyzer ISIS 300. The amount of Ti in the sample after crystallization was $5.68 \mathrm{wt} \%$, and after acid treatment and calcination $3.22 \mathrm{wt} \%$.

\section{Preparation of TS-1 and TS-2 catalysts}

The TS-1 catalyst (to 2,50 wt\% Ti) was prepared according to the method of Thangaraj et al. ${ }^{\mathbf{1 3}}$ The detailed characteristic of the catalyst was presented in our previous works $^{14-15}$

The TS-2 catalyst (to 3,50 wt\% Ti) was synthesized according to the method described by Reddy et al. ${ }^{\mathbf{1 6}}$. The detailed characteristic of the catalyst was presented in our previous works ${ }^{15,17}$. 


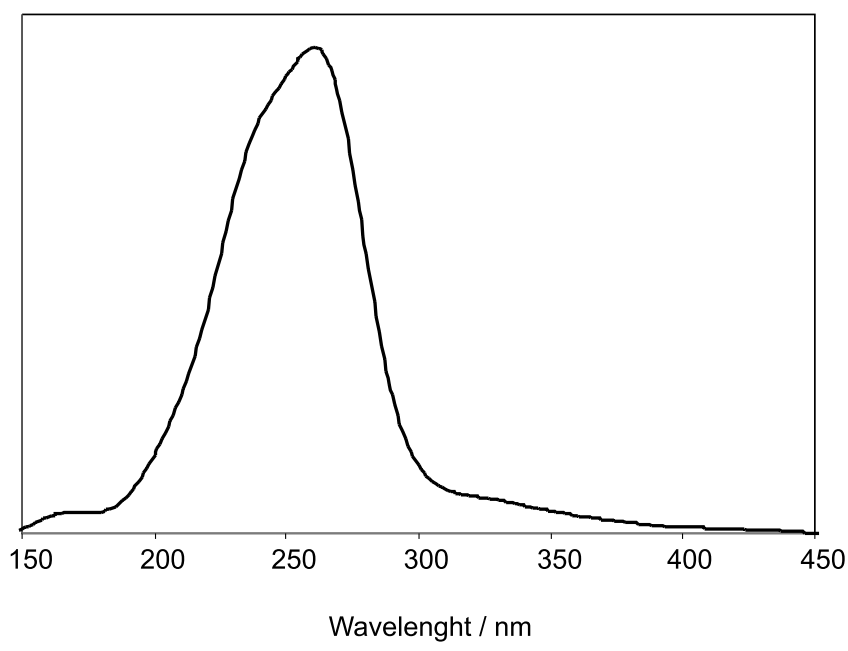

Figure 5. UV-vis spectra of the Ti-MWW catalyst after acid treatment and calcination

\section{Epoxidation procedure, apparatus and analytical methods}

In the epoxidation of allyl alcohol the following raw materials were used: allyl alcohol (98 wt \%, Fluka), the TS-1, TS-2 and Ti-MWW titanium silicalite catalysts (prepared at the Institute of Organic Chemical Technology, West Pomeranian University of Technology, Szczecin), hydrogen peroxide (30 wt \% water solution, P.O.Ch. Gliwice, Poland) and methanol (analytical grade., P.O.Ch. Gliwice, Poland).

The process of allyl alcohol epoxidation was carried out under atmospheric pressure in a glass reactor equipped with a reflux condenser, thermometer, mechanical stirrer and a dropping funnel. The substrates in proper amounts were introduced into the reactor in the following sequence: titanium-silicalite catalyst, allyl alcohol and methanol as a solvent. When the temperature reached a target value 30 $\mathrm{wt} \%$ water solution of hydrogen peroxide was dropped in. The process was conducted for a certain amount of time, then the content of the reactor was weighed and the product was analysed. The technological parameters used in the epoxidation over TS-1, TS-2 and Ti-MWW catalysts were as follows: temperature $20^{\circ} \mathrm{C}$, the molar ratio $\mathrm{AA} /$ $\mathrm{H}_{2} \mathrm{O}_{2}$ 1:1, methanol concentration $80 \mathrm{wt} \%$ and reaction time $3 \mathrm{~h}$.

In order to make mass balances of the syntheses performed, the following analyses were made: unreacted hydrogen peroxide was iodometrically determined ${ }^{\mathbf{1 8}}$, glycerine formed in the process was potentiometrically determined ${ }^{19}$, the other products and the unreacted allyl alco- hol were determined by gas chromatography. The chromatographic analyses were performed on a FOCUS apparatus equipped with a flame-ionization detector (FID), using a capillary column Quadrex $30 \mathrm{~m} \times 250 \mu \mathrm{m} \times 0,25 \mu \mathrm{m}$ packed with methylsiloxane modified with phenyl groups. The parameters of chromatographic separation were as follows: helium pressure $50 \mathrm{kPa}$, sensitivity 10 , the temperature of the sample chamber $150^{\circ} \mathrm{C}$, detector temperature $250^{\circ} \mathrm{C}$. The thermostat temperature was programmed in the following way: izothermally $40^{\circ} \mathrm{C}$ for $3 \mathrm{~min}$, followed by an increase at the rate $10^{\circ} \mathrm{C} / \mathrm{min}$ to $250^{\circ} \mathrm{C}$, izothermally $250^{\circ} \mathrm{C}$ for $5 \mathrm{~min}$, cooling to $60^{\circ} \mathrm{C}$. After the calculation of the mass balance for each synthesis, the main functions describing the process were determined, i.e. the selectivity of transformation to glycidol in relation to the allyl alcohol consumed, the conversion of allyl alcohol, the selectivity of transformation to organic compounds in relation to hydrogen peroxide consumed. These functions were calculated according to the following formula:

Selectivity of transformation to glycidol, in relation to allyl alcohol consumed $\left(S_{\text {glyc/AA }}\right)$ :

$\mathrm{S}_{\mathrm{glyc} / \mathrm{AA}}=\frac{\text { amount of glycidol obtained (mol) }}{\text { amount of allyl alcohol consumed (mol) }} * 100 \%$

Conversion of allyl alcohol $\left(\mathrm{C}_{\mathrm{AA}}\right)$ :

$\mathrm{C}_{\mathrm{AA}}=\frac{\text { amount of allyl alcohol consumed (mol) }}{\text { initial amount of allyl alcohol (mol) }} * 100 \%$

Selectivity of transformation to organic compounds in relation to hydrogen peroxide consumed $\left(\mathrm{S}_{\mathrm{org} / \mathrm{H} 2 \mathrm{O} 2}\right)$ : $\mathrm{S}_{\text {org } / \mathrm{H} 202}=\frac{\text { amount of organic comp. obtained (mol) }}{\text { amount of } \mathrm{H}_{2} \mathrm{O}_{2} \text { consumed }(\mathrm{mol})} * 100 \%$

The conversion of hydrogen peroxide was calculated in a similar way as the conversion of allyl alcohol. The selectivity of transformations to by-products: glycerine, bis(allyl) ether and allyl-glycidyl ether were calculated in a similar way as the selectivity of transformation to glycidol.

\section{RESULTS AND DISCUSSION}

Epoxidation of allyl alcohol over titanium-silicalite catalysts by a $30 \mathrm{wt} \%$ water solution of hydrogen peroxide in methanol as a solvent leads to glycidol (2,3-epoxy-1propanol) as the main product, which in the reaction conditions is partly hydrated to glycerine.

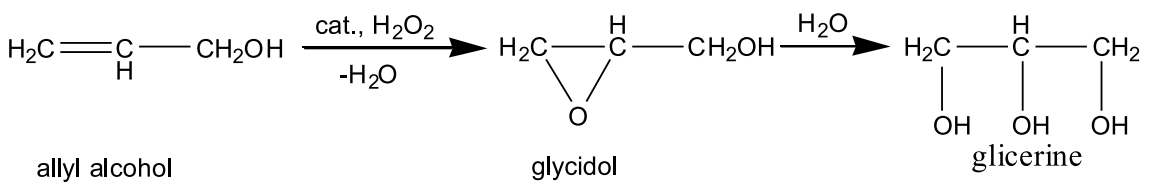

Depending on the conditions of epoxidation, also small amounts of ethers (bis(allyl) ether and allyl-glycidyl ether) are formed.
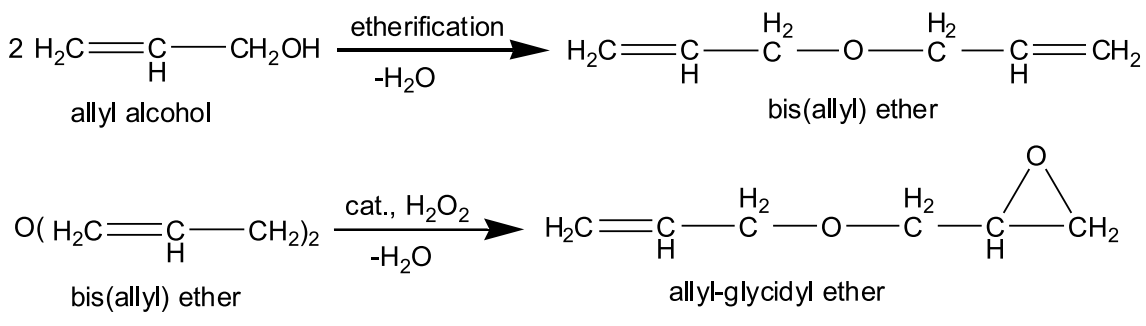
The influence of the titanium-silicalite catalyst concentration on the epoxidation of allyl alcohol over TS-1, TS2 and Ti-MWW catalysts was tested in the range of its variation from 0.1 to $5.0 \mathrm{wt} \%$. The obtained results present Figs. $6-8$ (the changes of the following process functions: the selectivity of transformation to glycidol in relation to consumed allyl alcohol, the conversion of allyl alcohol, the selectivity of transformation to organic compounds in relation to consumed hydrogen peroxide). The conversion of hydrogen peroxide amounted to over 95 mol\% and was not presented.

Figure 6 shows that in the case of TS- 1 and TS- 2 catalysts the best catalyst concentration is $1 \mathrm{wt} \%$ in order to achieve the highest selectivity to glycidol. The increase in these catalysts concentration causes the hydrolysis of epoxide ring and glicerine formation. The titanium silicalite catalysts take part in the hydrolysis of glycidol through the bonding of glycidol in active centers and polarization of epoxide ring. When the process is carried out in the presence of Ti-MWW catalyst the selectivity of the transformation to glycidol is constant in the whole catalyst concentration range and equals to $42-44 \mathrm{~mol} \%$.

The conversion of allyl alcohol increases with the increase of the TS- 1 and Ti-MWW catalysts concentration, for TS-1 from $40 \mathrm{~mol} \%$ to $64 \mathrm{~mol} \%$ and for Ti-MWW from $74 \mathrm{~mol} \%$ to $84 \mathrm{~mol} \%$ - Fig. 7. In the range of low Ti-MWW catalyst concentration $(0.1-1.0 \mathrm{wt} \%)$ the conversion of allyl alcohol increases to $90 \mathrm{wt} \%$ and then slightly decreases to $80 \mathrm{wt} \%$, which is probably related to the decomposition of hydrogen peroxide over the catalyst. The results obtained for TS-2 and Ti-MWW catalysts are comparable and highly beneficial for the epoxidation process - mainly because the amount of allyl alcohol recycled for the process decreases.

Figure 8 shows that for the TS- 1 catalyst concentrations in the range of $0.1-1.0 \mathrm{wt} \%$ the selectivity of transformation to organic compounds in relation to hydrogen peroxide consumed rises from $63 \mathrm{~mol} \%$ to $100 \mathrm{~mol} \%$ and for the higher catalyst concentrations it does not change. It shows that for the TS- 1 catalysts concentration in the range of $1.0-5.0 \mathrm{wt} \%$ the whole hydrogen peroxide introduced to the reactor takes part in the epoxidation process and does not decompose to oxygen and water. The epoxidation over Ti-MWW catalyst for the catalyst concentration $2.0-5.0 \mathrm{wt} \%$ shows the same course, but the

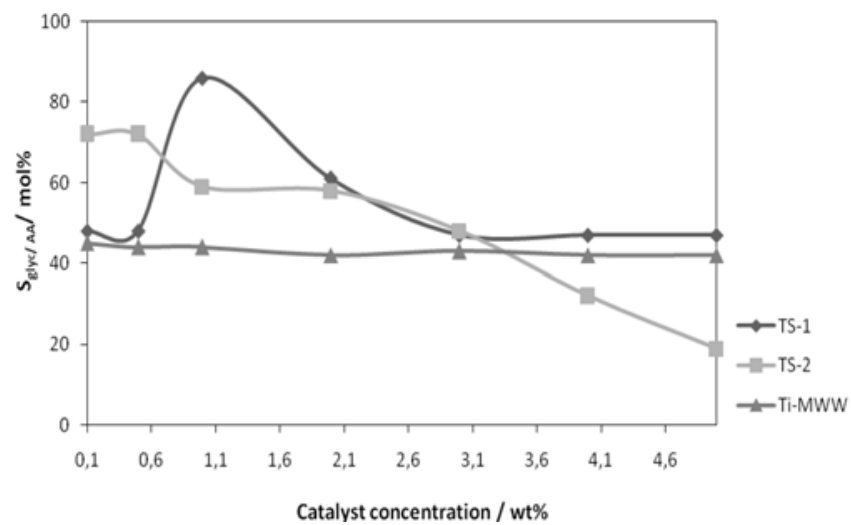

Figure 6. The influence of catalyst concentration on the selectivity of transformation to glycidol in relation to allyl alcohol consumed in the epoxidation over titanium-silicalite TS-1, TS-2 and Ti-MWW catalysts

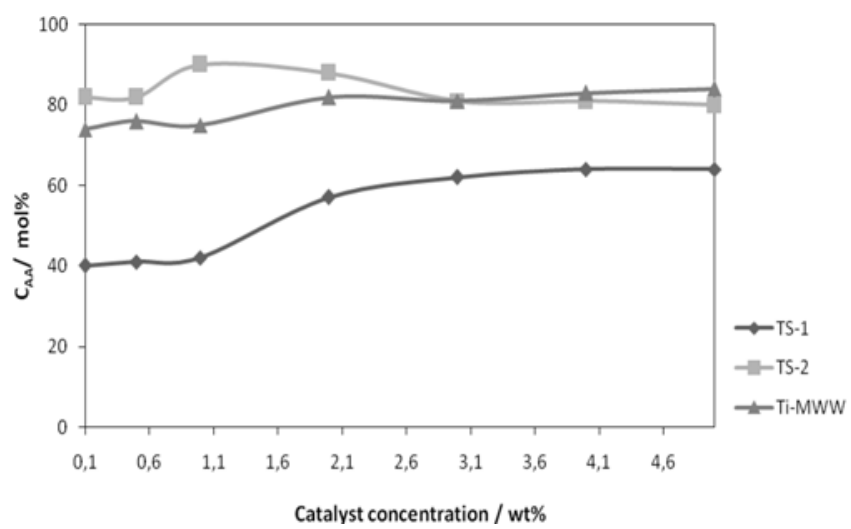

Figure 7. The influence of catalyst concentration on the conversion of allyl alcohol in the epoxidation over titanium-silicalite TS-1, TS-2 and Ti-MWW catalysts

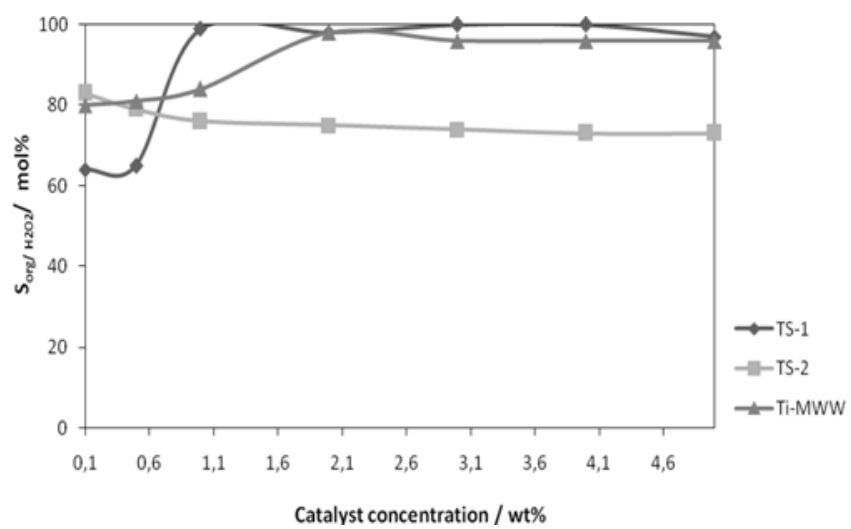

Figure 8. The influence of catalyst concentration on the selectivity of transformation to organic compounds in relation to hydrogen peroxide consumed in the epoxidation over titanium-silicalite TS-1, TS-2 and Ti-MWW catalysts

values of the selectivity of transformation to organic compounds in relation to hydrogen peroxide consumed are slightly lower (about $96 \mathrm{~mol} \%$ ). The selectivity of transformation to organic compounds in relation to hydrogen peroxide consumed for the TS- 2 catalyst is almost constant and amounts to $72-82 \mathrm{~mol} \%$.

\section{CONCLUSIONS}

The presented results showed that the Ti-MWW catalyst can be applied as a catalyst in the epoxidation of allyl alcohol with hydrogen peroxide. The selectivity of transformation to glycidol for Ti-MWW catalyst is lower than for classical titanium silicalite TS- 1 and TS-2 catalysts. Ti-MWW is more hydrophilic than TS-1 and TS-2 due to the silanols on the exterior surface and on the defect sites formed between the layers. It causes greater activity in the reaction of opening the epoxide ring in glycidol. For this reason the selectivity of transformation to glycidol in relation to allyl alcohol is lower than on TS-1 and TS-2, especially in the region of the low concentration of the examined catalysts $-0.1-1.0 \mathrm{wt} \%$. The selectivity of transformation to organic compounds in relation to hydrogen peroxide for Ti-MWW catalyst is comparable with TS-1. A little lower is in the presence of TS-2. Conversion of allyl alcohol over the Ti-MWW catalyst is similar for TS2 in the examined region of concentrations of catalysts ( 0.1 $-5.0 \mathrm{wt} \%$ ). Both conversions are higher than on TS-1. 


\section{LITERATURE CITED}

1. Lowenstein, W. (1954). The distribution of aluminum in the tetrahedral of silicates and aluminates. Am. Mineralogist 39, $92-96$.

2. Taramasso, M., Perego, G. \& Notari, B. (1983). Preparation of porous crystalline synthetic material comprised of silicon and titanium oxides. US Pat. 4410501.

3. Chen, X., Fan, Z., Quan, X. \& Wei, K. (2006). Epoxidation of allyl alcohol to glycidol on Ti-MWW molecular sieves. Chin. J. Catal. 27(3), $285-290$.

4. Wu, P., Tatsumi, T., Komatsu, T. \& Yashima, T. (2001). A novel titano-silicalite with MWW structure: I. Hydrothermal synthesis, elimination of extraframework titanium, and characterizations. J. Phys. Chem. B 105(15), 2897 - 2905. DOI: 10.1021/jp002816s.

5. Degnan, T. (2003). The implications of the fundamentals of shape selectivity for the development of catalysts for the petroleum and petrochemical industries. J. Catal. 216(1-2), 32 - 46. DOI: 10.1016/S002-9517(02)00105-7.

6. Fan, W., Wu, P., Namba, S. \& Tatsumi, T. (2006). Synthesis and catalytic properties of a new titanosilicate molecular sieve with the structure analogous to MWW-type lamellar precursor. J. Catal. 243(1), 183 - 191. DOI: 10.1016/j.cat.2006.07.003.

7. Wu, P. \& Tatsumi, T. (2003). A novel titanosilicate with MWW structure III. Highly efficient and selective production of glycidol through epoxidation of allyl alcohol with $\mathrm{H}_{2} \mathrm{O}_{2} . J$. Catal. 214, 317 - 326. DOI: 10.1016/30021-9517(02)00170-7.

8. Wu, P., Tatsumi, T., Komatu, T. \& Yashima, T. (2002). A novel titanosilicate with MWW structure: II. Catalytic properties in the selective oxidation of alkenes. J. Catal. 202(2), 245 - 255. DOI: 10.1006/j.cat.2001.3278.

9. Wu, P. \& Tatsumi, T. (2002). Preparation of B-free TiMWW through reversible structural conversion. Chem. Commun. 1026 - 1027.

10. Wu, P., Liu, Y., He, M. \& Tatsumi, T. (2004). A novel titanosilicalite with MWW structure. Catalytic properties in selective epoxidation of diallyl ether with hydrogen peroxide. J. Catal. 228(1), 183 - 191. DOI: 10.1016.j.cat.2004.09.001.

11. Song, F., Liu, Y., Wu, H. \& He, M. (2006). A novel titanosilicate with MWW structure: Highly effective liquidphase ammoximation of cycloheksanone. J. Catal.237(2), 359 - 367. DOI: 10.1016/j.cat.2005.11.018.

12. Wu, P., Tatsumi, T., Komatsu, T. \& Yashima, T. (2001). A novel titanosilicate with MWW structure. I. Hydrothermal synthesis, elimination of extraframework titanium, and characterizations. J.Phys. Chem. B 105(15), 2897 - 2905.DOI: 10.1021/jp002816s.

13. Thangaraj, A., Kumar, R. \& Ratnasamy, P. (1990). Direct catalytic hydroxylation of benzene with hydrogen peroxide over titanium-silicate zeolites. Appl. Catal. 57, L1-L3. DOI: 10.1016/S0166-9843(00)807,8-6.

14. Wróblewska, A. Ławro, E. \& Milchert, E. (2008). Influence of process parameters on the epoxidation of 2-buten1-pl over titanium silicalite TS-1 catalyst. Chem. Pap. 62(2) 147 - 153. DOI: 10.2478/s11696-008-0004-4.

15. Wróblewska, A. (2008). Epoxidation of allylic compounds with hydrogen peroxide over titanium silicalite catalysts. Prace naukowe Politechniki Szczecińskiej, Instytut Technologii Chemicznej Organicznej, No. 608, Szczecin (in Polish).

16. Reddy, J.S., Kumar, R. \& Ratnasamy, P. (1990). Titanium silicalite-2: synthesis, characterization and catalytic properties. Appl. Catal. 58, L1-L4.

17. Wróblewska, A. \& Milchert, E. (2007). Epoxidation of allyl alcohol with hydrogen peroxide over titanium silicalite TS-2 catalyst. J. Chem. Technol. Biotechnol. 82, 681 - 686. DOI: $10.1002 /$ jtb.1739.

18. Brill, W. F. (1968). The origin of epoxides in the liquid phase oxidation of olefins with molecular oxygen, J. Am. Chem. Soc. 85, 141.
19. Golowa, B. M., Motowiljak, L. W., Politanskij, S. F., Stjepanow, M. W. \& Czeljadin, W. T. (1974). Establishing the products of glycerol obtained by hydroxylation of allyl alcohol, Zawod. lab. 40, 1192 (in Russian). 